Reprod. Nutr. Dévelop., 1983, 23 (4), 755-764.

\title{
Plasma inorganic phosphorus concentration during eggshell formation. II. - Inverse relationships with intestinal calcium content and eggshell weight
}

\author{
B. SAUVEUR, P. MONGIN
}

with the technical assistance of Huguette ANTOINE

Station de Recherches avicoles, I.N.R.A. Nouzilly, 37380 Monnaie, France.

Summary. This paper reports two experiments. In the first experiment, 51 laying hens were killed at four different stages of eggshell formation $16,10,14$ or $16 \mathrm{~h}$ after a previous oviposition). The individual contents of the duodenum and jejunum were studied for soluble $\mathrm{Ca}$ concentration (Cas). The Cas increased in the duodenum and the proximal jejunum during shell secretion (14 and $16 \mathrm{~h}$ ); the values recorded in the distal jejunum were lower than those of the upper segments. At the same physiological stages, an inverse relationship was evident between Cas and plasma inorganic phosphorus content (Pi) $\langle\mathrm{r}=-0.7$ to -0.8 ). A negative relationship was also calculated between the $\mathrm{Pi}$ value at $14 \mathrm{~h}$ and the shell weight of the last two eggs produced before slaughter.

In the second experiment, blood samples were taken from 35 hens at 10, 12, 14 and $16 \mathrm{~h}$ after oviposition. The surface under the Pi curve was calculated for each hen and used as an estimation of bone mobilization. The weight of the shell secreted during the sampling period was negatively correlated with this $\mathrm{Pi}$ surface $(\mathrm{r}=-0.68)$ when studied in a covariance analysis including egg weight.

The different possible relationships among the factors of intestinal ability to absorb calcium, bone mobilization, inorganic phosphatemia and shell deposition in utero are considered.

\section{Introduction.}

It has been shown by Feinberg et al. (1937), and in more detail by Mongin and Sauveur (1979), that the amount of inorganic phosphorus in the plasma of laying hen $(\mathrm{Pi})$ increases sharply between 10 and $14 \mathrm{~h}$ after the previous oviposition. This period corresponds to the beginning of eggshell deposition in the uterus and is also characterized by a sharp increase in phosphorus excretion by the kidney (Prashad and Edwards, 1973). Thus, it is tempting to interpret this increase in $\mathrm{Pi}$ as the result of acute bone mobilization linked to the need of calcium for eggshell formation.

During the previous study by Mongin and Sauveur (1979), it was noted that the shape of the Pi curve varied greatly among hens; in some birds, Pi increased up to the 18-h stage after oviposition, while it slowly returned to basal level after 12 or $14 \mathrm{~h}$ in most of the hens. As there are only two possible origins for 
eggshell calcium - the skeleton and the intestine - an experiment was undertaken to test whether the shape variations of the $\mathrm{Pi}$ curves could be related to individual differences in the ability of the intestine to absorb calcium.

In fact, if numerous studies have been conducted on intestinal calcium absorption during eggshell formation, individual differences have seldom been considered. Hurwitz and Bar (1965) were the first to show that duodenal and jejunal calcium absorption increased during eggshell calcification. They then demonstrated that diffusion was the most probable mechanism for the entry of $\mathrm{Ca}^{++}$into the intestinal mucosa (Bar and Hurwitz, 1969). The short-term regulation of intestinal calcium absorption has been shown to be independent of duodenal calcium-binding protein (Bar and Hurwitz, 1972) and of the renal activity of 25-hydroxycholecalciferol-1-hydroxylase (Montecuccoli et al., 1977). More recently, Mongin (1976b) and Nys and Mongin $(1980,1982)$ using a different methodology, confirmed that the rate of intestinal calcium absorption during eggshell formation is principally controlled by the chemical gradient of this element.

So, the level of soluble calcium in intestinal contents at given physiological stages has been used in the present study to estimate the individual ability to absorb calcium. Eggshell weight was recorded simultaneously to show any putative effect of calcium origin - intestinal or skeletal - on eggshell deposition.

\section{Material and methods.}

Experiment 1. - The first experiment was conducted with 51 mediumheavy, brown-egg laying hens (Warren ISA) during the second half of their laying year. The animals were housed in individual cages equipped with an automatic oviposition recording system and situated in a room with constant temperature and humidity. The lights were on for $16 \mathrm{~h}$ a day. The hens were fed ad libitum a complete commercial diet containing $30 \mathrm{~g}$ of calcium $/ \mathrm{kg}, 4 \mathrm{~g}$ of available phosphorus $/ \mathrm{kg}$ and $2000 \mathrm{IU}$ of vitamin $\mathrm{D}_{3} / \mathrm{kg}$.

Variable numbers of hens (see table 1) were slaughtered at different stages of egg formation, i.e. $6,10,14$ or $16 \mathrm{~h}$ after the previous oviposition. The presence of an egg in the oviduct was verified by rectal palpation. A blood sample was taken from the wing vein and, immediately afterwards, the hens were killed by an overdose of penthobarbital. The digestive tract was immediately exposed and the contents of the duodenum and the upper and lower jejunum were collected according to Mongin (1976a). After centrifugation, the supernatants were used for measuring the soluble calcium contents (Cas) by flame photometry (Eppendorf). Plasma inorganic phosphorus was measured after dialysis of plasma samples in a Technicon Auto Analyser.

When possible, the eggs of each hen were collected for one to three weeks before slaughter. The physiological parameters recorded were correlated with the shell weight, taking into account the last egg gathered, the last 2 eggs gathered, or all the eggs gathered.

Experiment 2. - The second experiment was conducted with 35 Warren ISA hens-housed as described in experiment 1. Blood samples, taken from the 
wing vein of each hen at 10, 12, 14 or $16 \mathrm{~h}$ after oviposition, were used for inorganic phosphorus analysis. The shells of eggs laid on the day following sampling were weighed in order to study the relationship between bone mobilization and the amount of deposited eggshell.

Bone mobilization was estimated by the surface under the Pi curve between 10 and $16 \mathrm{~h}$ after the previous oviposition. This surface was calculated using $S=2\left(P_{12}+P_{14}\right)+P_{16}-5 P_{10}$, in which $P_{10}, P_{12}, P_{14}$ and $P_{16}$ were the values of $\mathrm{Pi}$ at $10,12,14$ and $16 \mathrm{~h}$, respectively, after oviposition. The validity of this formula, whatever the form of the Pi curve, is demonstrated in figure 1.
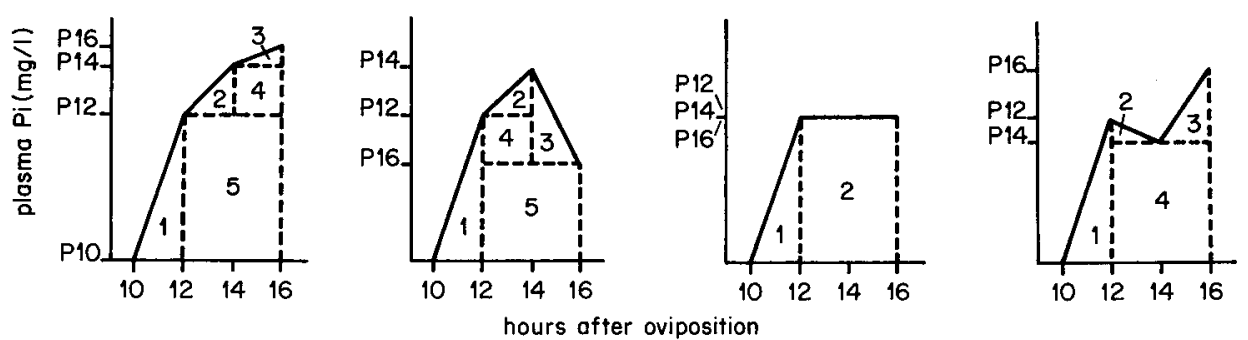

Surfaces:

\begin{tabular}{l}
$1 ;(\mathrm{P} 12-\mathrm{P} 10) \times 2 / 2$ \\
$2 ;(\mathrm{P} 14-\mathrm{P} 12) \times 2 / 2$ \\
$3 ;(\mathrm{P} 16-\mathrm{P} 14) \times 2 / 2$ \\
$4 ;(\mathrm{P} 14-\mathrm{P} 12) \times 2$ \\
$5 ;(\mathrm{P} 12-\mathrm{P} 10) \times 4$ \\
\hline
\end{tabular}

$$
\begin{aligned}
& 1 ;(\mathrm{P} 12-\mathrm{P} 10) \times 2 / 2 \\
& 2 ;(\mathrm{P} 14-\mathrm{P} 12) \times 2 / 2 \\
& 3 ;(\mathrm{P} 14-\mathrm{P} 16) \times 2 / 2 \\
& 4 ;(\mathrm{P} 12-\mathrm{P} 16) \times 2 \\
& 5 ;(\mathrm{P} 16-\mathrm{P} 10) \times 4 \\
& \hline \\
&-5 \mathrm{P} 10+2 \mathrm{P} 12 \\
&+2 \mathrm{P} 14+\mathrm{P} 16
\end{aligned}
$$$$
5-5 \mathrm{P} 10+2 \mathrm{P} 12
$$

$$
\begin{aligned}
& 1 ;(P 12-P 10) \times 2 / 2 \\
& 2 ;(P 12-P 10) \times 4 \\
& \hline-5 P 10+5 P 12
\end{aligned}
$$$$
1 ;(\mathrm{P} 12-\mathrm{P} 10) \times 2 / 2
$$$$
2 ;(P 12-P 14) \times 2 / 2
$$$$
3 ;(P 16-P 14) \times 2 / 2
$$$$
4 ;(P 14-P 10) \times 4
$$$$
-5 \mathrm{P} 10+2 \mathrm{P} 12
$$$$
+2 \mathrm{P} 14+\mathrm{P} 16
$$

Common formula : $2(\mathrm{P} 12+\mathrm{P} 14)+\mathrm{P} 16-5 \mathrm{P} 10$.

FIG. 1. - Some examples of calculation of the surface under the curve of plasma inorganic phosphorus concentration. Whatever the shape of the curve, the surface could be calculated by a single formula.

\section{Results.}

Experiment 1. - The mean values of plasma $\mathrm{Pi}$ and of intestinal soluble calcium recorded at different times after oviposition are reported on table 1. Intestinal $\mathrm{Ca}$ content increased between 6 and $10 \mathrm{~h}$ and then stabilized between 10 and $14 \mathrm{~h}$. A new significant increase was seen between 14 and $16 \mathrm{~h}$, principally in the duodenum and the upper jejunum. The Cas value recorded in the distal jejunum was more constant and significantly lower than those of the two upper segments. The peak of the mean $\mathrm{Pi}$ values was found at $14 \mathrm{~h}$ after oviposition ; it was followed by a small decrease between 14 and $16 \mathrm{~h}$.

The relationships between Cas in the three intestinal segments and $\mathrm{Pi}$ are indicated on table 2 while the illustration on figure 2 concerns only the duodenum. 
TABLE 1

Experiment 1. Plasma inorganic phosphorus and intestinal soluble calcium concentrations in relation to egg formation (Values of $\mathrm{x} \pm \sigma / \sqrt{ } \mathrm{n}$ )

\begin{tabular}{|c|c|c|c|c|c|}
\hline \multirow{2}{*}{$\begin{array}{l}\text { Hours after } \\
\text { oviposition }\end{array}$} & \multirow{2}{*}{$\begin{array}{c}\text { Plasma } \\
\mathrm{Pi} \\
(\mathrm{mg} / \mathrm{l})\end{array}$} & \multicolumn{4}{|c|}{ Intestinal $\mathrm{Ca} \mathrm{s}$ (mEq/I supernatant) } \\
\hline & & Duodenum & $\begin{array}{l}\text { Upper } \\
\text { jejunum }\end{array}$ & $\begin{array}{l}\text { Lower } \\
\text { jejunum }\end{array}$ & Mean \\
\hline 6 & $33.7 \underset{(5)^{*}}{ \pm} 2.6^{a}$ & $34.7 \underset{\frac{ \pm}{(5)}}{ \pm} 4.0$ & $31.2 \frac{ \pm}{(5)} 1.9$ & $26.3 \frac{ \pm}{(5)} 3.9$ & $30.8^{\mathrm{a}}$ \\
\hline 10 & $40.3_{(10)}^{ \pm} 2.7^{b}$ & $\begin{array}{c}46.7 \pm 5.3 \\
(10)\end{array}$ & $51.3 \pm \frac{ \pm}{(9)} 5.9$ & $41.2 \frac{ \pm}{(6)} 10.3$ & $47.0^{\mathrm{b}}$ \\
\hline 14 & $52 .{ }_{(13)} \pm 3.2^{\mathrm{d}}$ & $\begin{array}{c}43.0 \pm 6.0 \\
(13)\end{array}$ & $\begin{array}{c}47.0 \pm 7.4 \\
(13)\end{array}$ & $41.1 \frac{ \pm}{(8)} 10.0$ & $44.1^{b}$ \\
\hline 16 & $46.5 \pm 2.0^{c}$ & $68.0 \pm 3.1$ & $\begin{array}{c}65.6 \pm 3.7 \\
(21)\end{array}$ & $43.6 \underset{(11)}{ } 6.2$ & $62.2^{c}$ \\
\hline Mean & & $54.2^{v}$ & $54.3^{v}$ & $39.6^{\mathrm{U}}$ & \\
\hline $\begin{array}{l}\text { () } \\
\text { Pi } \\
\text { Ca s } \\
\text { a, b, c, d } \\
u, v\end{array}$ & \multicolumn{5}{|c|}{$\begin{array}{l}: n^{\circ} \text { of recorded values. } \\
\text { : effect of physiological stage } P<0.001 . \\
\text { : effect of physiological stage } P<0.001 . \\
\text { effect of intestinal segment } P<0.01 . \\
\text { interaction : non-significant. } \\
: \text { means in the same column with a different superscript are significantly different } \\
(p<0.05) \text {. } \\
: \text { means in the same line with a different superscript are significantly different }\end{array}$} \\
\hline
\end{tabular}

TABLE 2

Experiment 1. Correlation coefficients ( $r$ values) between plasma inorganic phosphorus (mg/l) and intestinal soluble calcium concentrations $(\mathrm{mEq} / \mathrm{l})$ measured on the same hens. Effect of the physiological stage of egg formation and of the intestinal segment

\begin{tabular}{|c|c|c|c|}
\hline \multirow{2}{*}{ Hours after oviposition } & \multicolumn{3}{|c|}{ Intestinal segment } \\
\hline & Duodenum & Upper jejunum & Lower jejunum \\
\hline 6 & $-0.68(5)^{+}$ & $-0.54(5)$ & 0.17 \\
\hline 10 & $-0.42(10)$ & $-0.22(9)$ & -0.41 \\
\hline 14 & $-0.89(13)^{* * *}$ & $-0.88(13)^{* * *}$ & $-0.93(8)^{* *}$ \\
\hline 16 & $-0.61(23)^{* * *}$ & $-0.70(21)^{* * *}$ & $-0.65(11)^{*}$ \\
\hline Common regressions $\left\{^{r}\right.$ & $-0.74(36)^{* * *}$ & $-0.79(34)^{* * *}$ & $-0.81(19)^{* * *}$ \\
\hline 14 and $16-h$ stages ${ }^{++}$t slope & -0.44 & -0.40 & -0.36 \\
\hline $\begin{array}{ll}\text { Common regressions } & \\
6 \text { to } 16-h \text { stages } & \left\{\begin{array}{l}r \\
\text { slope }\end{array}\right.\end{array}$ & $\begin{array}{l}-0.63(51)^{* * *} \\
-0.38\end{array}$ & $\begin{array}{l}-0.70(48)^{* * *} \\
-0.35\end{array}$ & $\begin{array}{l}-0.70(30)^{* * * *} \\
-0.30\end{array}$ \\
\hline
\end{tabular}

$+: n^{\circ}$ of pairs of values used for $r$ calculation.

Significance level of $r:{ }^{*}: P<0.05 ;{ }^{* *}: P<0.01 ;{ }^{* *}: P<0.001$.

++ : covariance analysis within each of the three intestinal segments indicated no significant difference between the slopes in regard to the 4 physiological stages and highly significant differences $(p<0.001)$ between the means of $\mathrm{Pi}$. We then computed the correlations common to two or four stages; the coefficients of these correlations are given here with their corresponding slope values. 
The values of the correlation coefficients (table 2) clearly show that there was an inverse relationship between the calcium content of the intestinal supernatant and the value of $\mathrm{Pi}$ recorded at the same time. This relationship was non-significant at 6 or $10 \mathrm{~h}$ after oviposition but highly significant during eggshell formation (14 and $16 \mathrm{~h}$ after oviposition); similar results were recorded for the three intestinal segments studied.

A covariance analysis performed on these data showed that the slope of the relationships between $\mathrm{Cas}$ and $\mathrm{Pi}$ remained constant for the four studied physiological stages; only intercepts with the ordinate varied significantly ( $p<0.001$ ) (fig. 2). The slope values (b) and the correlation coefficients ( $r$ ) of the common regressions $(\mathrm{Pi})=\mathrm{b}(\mathrm{Cas})+\mathrm{a}$ for the 14 and 16-h stages only or the 6 to 16 -h stages are also given on table 2 .

The values of the correlation coefficients reported on table 3 also seem to indicate that, at least at short-term, the hens secreting poor shells were characterized by a high Pi value at $14 \mathrm{~h}$. On the contrary, Cas concentration in the duodenum was positively correlated with the amount of deposited eggshell, and the same observation was true for jejunal $\mathrm{Ca}$ content at $16 \mathrm{~h}$. These

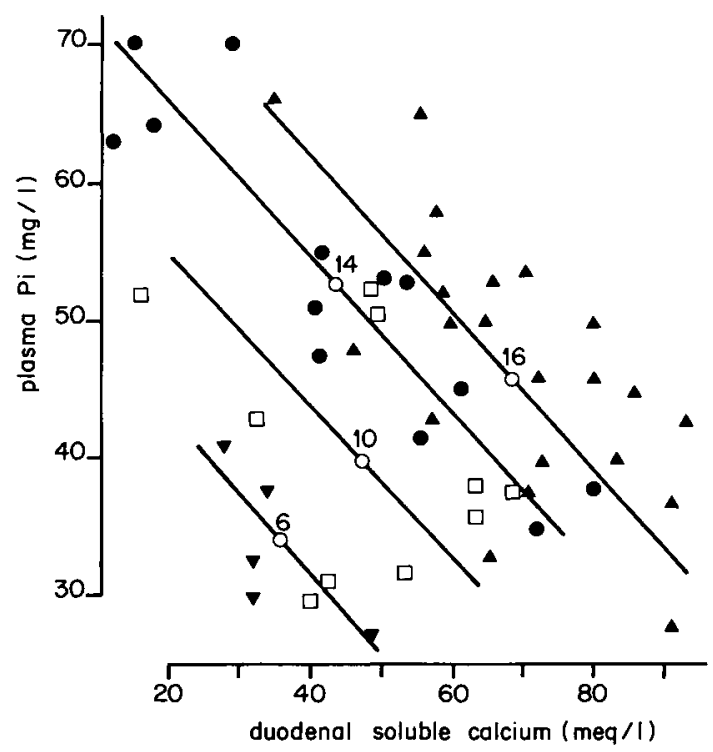

FIG. 2. - (Experiment 1) Inverse relationship between soluble calcium extracted from the duodenal supernatant (in $\mathrm{mEq} / \mathrm{l}$ ) and the amount of inorganic phosphorus in the plasma (mg/l). The hens were slaughtered at four different stages of egg shell formation $16,10,14$ or 16 hours after a previous oviposition). The open circles indicate the mean value of each stage. 6 hours : $\nabla$; 10 hours : $\square ; 14$ hours : $; 16$ hours : $\Delta$.

$\begin{array}{lcc} & \text { All stages } & 14+16 \mathrm{~h} \text { only } \\ \text { r } & -0.63^{* * *} & -0.74^{* * *} \\ \text { b } & -0.38 & -0.44 \\ \text { F slope } & \text { N.S. } & \text { N.S. } \\ \text { F intercept } & 17^{* *} & \text { N.S. }\end{array}$


TABLE 3

Experiment 1. Correlation coefficients (r values) between eggshell weight and plasma inorganic phosphorus or intestinal soluble calcium concentrations. Effect of the physiological stage at the moment of slaughter

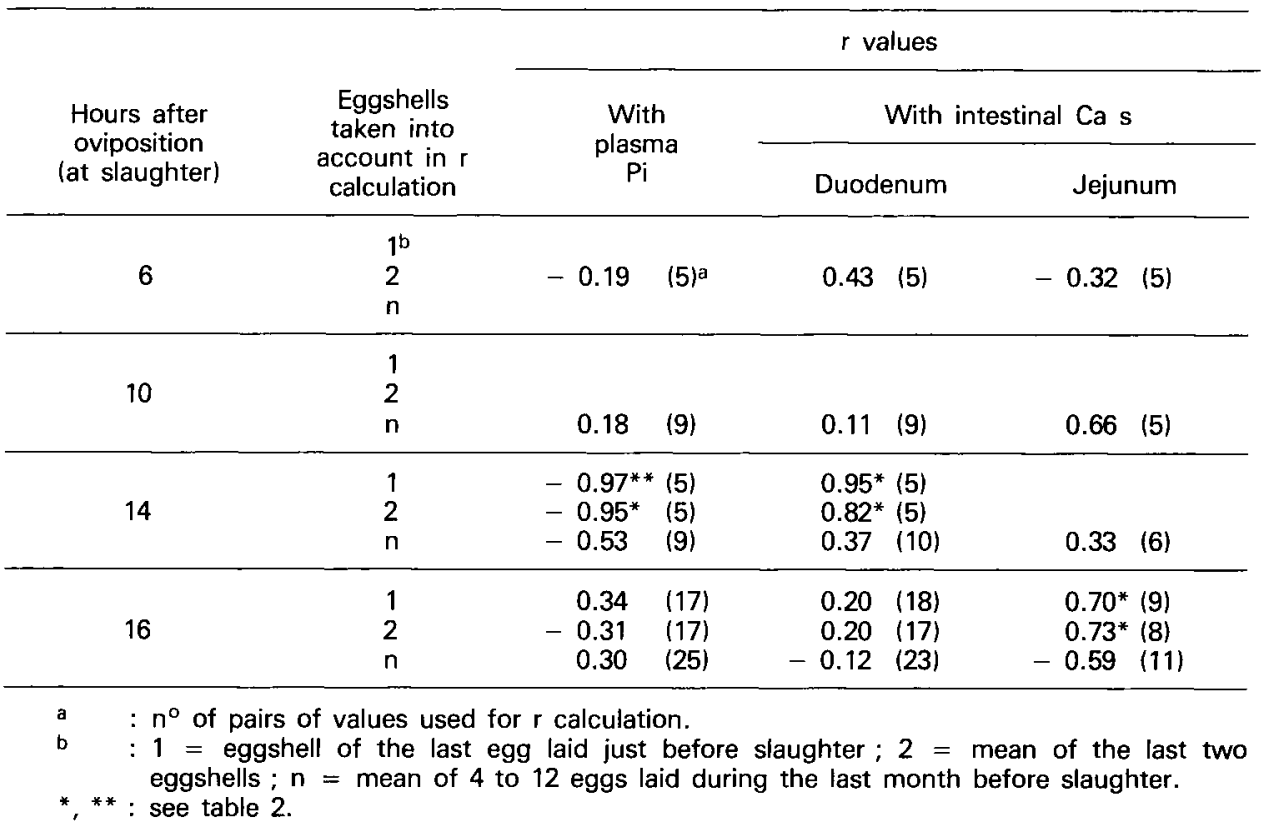

relationships became proportionally weaker as the average eggshell weights, used in calculating the $r$ coefficients, were estimated from eggs progressively anterior to the slaughtering day. Moreover, no relationship was evident between eggshell weight and $\mathrm{Pi}$ at $16 \mathrm{~h}$.

Experiment 2. - For studying the relationships between the amount of deposited eggshell and bone mobilization estimated by the surface under the $\mathrm{Pi}$ curve, the eggs were separated into there classes according to weight (table 4). The class limits were chosen in order to obtain enough data within each class. The three regression lines obtained are shown on figure 3.

The data clearly demonstrate that an inverse relationship existed between eggshell deposition and so-called bone mobilization. Covariance analysis (table 4) indicated that the regression coefficient did not vary among the three classes of egg ; the common regression was: (eggshell weight) $(g)=-0.006$ (surface) $+a ;(r=-0.68 ; p<0.001)$.

\section{Discussion.}

The present study was undertaken firstly to test whether individual differences in plasma inorganic phosphorus concentration during eggshell formation could be related to individual differences in intestinal soluble calcium content. 
TABLE 4

Experiment 2. Relationships between egg shell weight and bone mobilisation estimated by the surface under the Pi curve between 10 and $16 \mathrm{~h}$ after oviposition.

Results of covariance analysis among three classes of egg weight

\begin{tabular}{|c|c|c|c|c|c|}
\hline $\begin{array}{l}\text { Class of } \\
\text { egg weight }\end{array}$ & $\begin{array}{l}\mathrm{N}^{\circ} \text { of } \\
\text { data (1) }\end{array}$ & $r$ & $\underset{b}{\text { Slope }}$ & $\begin{array}{c}\text { Intercept } \\
\text { a }\end{array}$ & $\begin{array}{l}\text { Level of } \\
\text { significance }\end{array}$ \\
\hline $\begin{aligned} & <57 \mathbf{g} \\
57 & -61 \mathbf{g} \\
& >61 \mathbf{g}\end{aligned}$ & $\begin{array}{r}7 \\
12 \\
14\end{array}$ & $\begin{array}{l}-0.58 \\
-0.90 \\
-0.62 \\
\end{array}$ & $\begin{array}{r}-0.0079 \\
-0.0066 \\
-0.0047 \\
\end{array}$ & $\begin{array}{l}5.19 \\
5.74 \\
6.01\end{array}$ & $\begin{array}{c}\text { N.S. } \\
* * * \\
* *\end{array}$ \\
\hline \multirow[t]{2}{*}{$\begin{array}{l}\text { Common } \\
\text { regression }\end{array}$} & & -0.68 & -0.0059 & & $* * *$ \\
\hline & \multicolumn{4}{|c|}{$\begin{array}{l}\text { comparison of slopes } \\
\text { comparison of intercepts }\end{array}$} & $\underset{* * *}{\text { N.S. }}$ \\
\hline
\end{tabular}

(1) Each datum corresponds to an egg ; during the formation of the eff, plasma inorganic phosphorus was recorded at $10,12,14$ and $16 \mathrm{~h}$ after oviposition (for details, see materials and methods).

N.S. : Non-significant $;{ }^{* *},{ }^{* *}$ : see table 2.

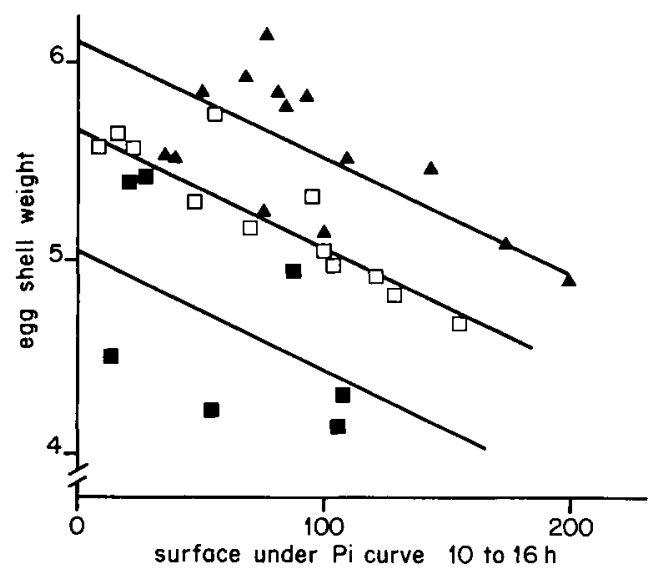

FIG. 3. - (Experiment 2). Inverse relationship between bone mobilisation estimated by the surface under the Pi curve (see methods) and eggshell weight. The three different curves correspond to three classes of egg weight : $<57 \mathrm{~g}: \mathbf{\square} ; 57-61 \mathrm{~g}: \square ;>61 \mathrm{~g}: \Delta ;$ a : intercept value. $\mathrm{ESW}=0.006 \mathrm{~S}+\mathrm{a} ; \mathrm{r}=-0.68^{* * *}$.

The results demonstrate that such a relationship actually existed : the higher the intestinal soluble calcium during eggshell formation, the lower was the simultaneous $\mathrm{Pi}$ value (14 and $16 \mathrm{~h}$ after oviposition).

The profile of intestinal soluble calcium content observed here was in good agreement with and completed that previously reported by Mongin (1976a). In the duodenum and upper jejunum this content increased twofold between 6 and $16 \mathrm{~h}$ after oviposition, i.e. during eggshell formation. Besides, the intestinal calcium content decreased between the duodenum and the lowest part of the 
jejunum; this decrease confirmed that there was considerable calcium absorption in the duodenum and upper jejunum, as previously observed by Hurwitz and Bar (1965) and Bar et al. (1976).

In the introduction to the present paper, we recalled the reasons why the soluble calcium content of the gut is a good predictor of the amount of absorbed calcium. The relationship between plasma inorganic phosphorus concentration and bone mobilization is discutable. It is known that intestinal absorption of total phosphorus slightly increases during eggshell formation (Hurwitz and Bar, 1965), but the exact effect of this process on plasma inorganic phosphorus concentration is not known. On the other hand, the urinary excretion of phosphate seems to follow rather than precede the increase of plasma concentration (Mongin and Sauveur, 1979). Thus, it seems that plasma inorganic phosphorus concentration may be considered as a satisfactory indirect estimator of bone mobilization.

If these hypotheses are admitted, the present results demonstrate that, as formerly seen in young chicks by Hurwitz, Bar and Cohen (1973), there could be an inverse relationship between intestinal calcium absorption and bone mobilization in the laying hen secreting an eggshell. These results also support the hypothesis, already formulated by Mongin and Sauveur (1979), that bone mobilization after the 12-h stage would depend on individual capacity to absorb calcium. The connection between these two physiological compartments is unknown, although a decrease in plasma ionic calcium and a parathyroid hormone discharge are the most probable events. Such a decrease has been observed after the 9-h stage by Luck and Scanes (1979), and the same authors have shown that plasma ionic calcium can be increased by injecting bovine PTH during eggshell formation (Luck, Sommerville and Scanes, 1980). The present impossibility of measuring the blood levels of endogenous PTH in the laying hen prevents further study of this.

Another new fact observed in the present study was the inverse relationship between plasma $\mathrm{Pi}$ value and eggshell deposition. There are two hypotheses for this observation. The most probable one is that a high $\mathrm{Pi}$ value by itself would have a negative effect on calcium carbonate precipitation in utero; many experiments have shown that excessive dietary phosphorus reduces eggshell quality and, recently, Miles and Harms (1982) calculated a correlation coefficient equal to - 0.98 between egg specific gravity and variations of plasma phosphorus obtained by dietary treatments. Many years ago, Simkiss (1968) summarized the negative effects of phosphates on eggshell formation. Thus, it is possible that when our hens were obliged to mobilize a large quantity of bone calcium due to poor intestinal calcium absorption, eggshell formation was decreased by the high Pi value.

The second hypothesis would be that hens with poor intestinal calcium absorption could not mobilize enough bone to provide for the total calcium requirement of the shell gland. Further studies are required to elucidate these problems. 
Résumé. Evolution de la phosphatémie durant la formation de la coquille de l'œuf chez la poule : relation inverse avec le calcium intestinal et le poids de la coquille sécrétée.

La forte élévation de teneur en phosphore inorganique du plasma ( $\mathrm{Pi}$ ) qui accompagne la formation de la coquille de l'œuf est un signe de mobilisation osseuse facile à appréhender et qui montre d'importantes variations individuelles (Mongin et Sauveur, 1979). Afin d'étudier si ces variations pourraient être dues à des déficiences d'absorption intestinale du calcium nécessaire à la formation de la coquille, on a abattu 51 poules à différents stades de formation de l'œuf (exactement à $6,10,14$ ou $18 \mathrm{~h}$ après une oviposition) et on a mesuré les teneurs en calcium soluble du contenu du duodénum et du jéjunum (Cas).

Les valeurs de Cas augmentent pendant la sécrétion de la coquille dans le duodénum et le jéjunum proximal tandis qu'elles sont constantes et toujours plus faibles dans le jéjunum distal. Une corrélation négative $(r=-0,7$ à $-0,8)$ existe entre Cas de chaque segment et la valeur de phosphatémie aux stades 14 et $16 \mathrm{~h}$. Pi à $14 \mathrm{~h}$ est également corrélé négativement avec le poids de coquille moyen des deux œufs précédant l'abattage.

Dans un autre essai, des échantillons de sang ont été prélevés sur 35 poules à 10,12 , 14 et $16 \mathrm{~h}$ après une oviposition. La surface sous la courbe de phosphatémie a été calculée pour chaque poule comme estimateur de la mobilisation osseuse. Le poids de la coquille sécrétée pendant cette période apparaît corrélé à - 0,68 avec cette surface lorsque le poids de l'œuf est introduit dans une analyse de covariance.

Ces résultats indiquent que, au cours de la formation de la coquille, la mobilisation osseuse intervient de façon complémentaire à l'absorption intestinale pour assurer l'approvisionnement en calcium de l'utérus. II est proposé que l'hyperphosphatémie qui en résulte puisse être, en tant que telle, un facteur défavorable au dépôt de la coquille.

\section{References}

BAR A., EISNER U., MONTECUCCOLI G., HURWITZ S., 1976. Regulation of intestinal calcium absorption in the laying quail : independent of kidney vitamin $D$ hydroxylation. J. Nutr., 106, 1336-1342.

BAR A., HURWITZ S., 1969. The accumulation of calcium in laying fowl intestine in vitro. Biochim. biophys. Acta, 183, 591-600.

BAR A., HURWITZ S., 1972. Relationship of duodenal calcium - binding protein to calcium absorption in the laying fowl. Comp. Biochem. Physiol., 41B, 735-744.

FEINBERG J. C., HUGHES J. S., SCOTT H. M., 1937. Fluctuations of calcium and inorganic phosphorus in the blood of the laying hen during the cycle of one egg. Poult. Sci., 16, 132-134.

HURWITZ S., BAR A., 1965. Absorption of calcium and phosphorus along the gastrointestinal tract of the laying fowl as influenced by dietary calcium and egg shell formation. J. Nutr., 86, 433-438.

HURWITZ S., BAR A., COHEN A., 1973. Regulation of calcium absorption by fowl intestine. Am. J. Physiol., 225, 150-154.

LUCK M. R., SCANES C. G., 1979. Plasma levels of ionized calcium in the laying hen (Gallus domesticus). Comp. Biochem. Physiol., 63A, 177-181.

LUCK M. R., SOMMERVILLE B. A., SCANES C. G., 1980. The effect of egg shell calcification on the response of plasma calcium activity to parathyroïd hormone and calcium in the domestic fowl (Gallus domesticus). Comp. Biochem. Physiol., 65A, 151-154.

MILES R. D., HARMS R. H., 1982. Relationship between egg specific gravity and plasma phosphorus from hens fed different dietary calcium, phosphorus and sodium levels. Poult. Sci, 61, 175-177.

MONGIN P., 1976a. Ionic constituents and osmolality of the small intestinal fluids of the laying hen. Br. Poult. Sci., 17. 383-392.

MONGIN P., 1976b. Compositions of crop and gizzard contents in the laying hen. Br. Poult. Sci., 17, 499-507. 
MONGIN P., SAUVEUR B., 1979. Plasma inorganic phosphorus concentration during egg shell formation. Effect of the physical form of the dietary calcium. Br. Poult. Sci., 20, 401-412.

MONTECUCCOLI G., HURWITZ S., COHEN A., BAR A., 1977. The role of 25-hydroxycholecalciferol-1-hydrolase in the responses of calcium absorption to the reproductive activity in birds. Comp. Biochem. Physiol., 57A, 335-339.

NYS Y., MONGIN P., 1980. Jejunal calcium permeability in laying hens during egg formation. Reprod. Nutr. Dévelop., 20, 155-161.

NYS Y., MONGIN P., 1982. Transport of electrolytes and water in the upper jejunum of the fowl : in vivo perfusion. Pflügers Arch., 392, 251-256.

PRASHAD D. N., EDWARDS N. A., 1973. Renal excretion of calcium, phosphate and magnesium in the laying fowl. Proc. 4th European Poult. Conf., London, 57-62.

SIMKISS K., 1968. The structure and formation of the shell and shell membranes, 3-25. In CARTER T. C. Egg quality. A Study of the hen's egg. Oliver and Boyd Ltd, Edinburgh. 